\title{
KETERKAITAN INSTRUMEN KEBIJAKAN MONETER DENGAN NERACA PEMBAYARAN DI INDONESIA
}

\author{
Indra Maipita \\ Fakultas Ekonomi Universitas Negeri Medan \\ Sumatera Utara, Indonesia \\ Email: imaipita@unimed.ac.id
}

\begin{abstract}
This study aims to determine the monetary policy variable linkages with Indonesia's balance of payments. Using svar and IRF analysis found that the level of $\alpha=0.05$, variable monetary policy instruments such as open market operation $(O P T)$, the minimum reserve requirement (GWM), and the discount rate ( $r D i s k$ ) has a significant relationship with the variable balance of payments (BOP). In fact, all the macroeconomic variables also significantly affect the balance of payments variables, except the variable domestic interest rates. This means that there is a close link between monetary policy instruments with the balance of payments in Indonesia in the period of the study.
\end{abstract}

Keywords: Instruments of Monetary policy, Balance of payment, SVAR, IRF

\section{PENDAHULUAN}

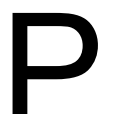

ersoalan mendasar hampir dari seluruh negara berkembang adalah tingginya tingkat pengangguran dan inflasi serta masalah current account deficit (external imbalance). Untuk mengatasi hal ini diperlukan tingkat pertumbuhan ekonomi yang tinggi. Namun kebijakan ekspansif untuk meningkatkan pertumbuhan seringkali menyebabkan pertumbuhan demand yang tinggi tidak sebanding dengan kapasitas supply yang ada. Hal ini akan berdampak pada masalah external balance, yaitu: (1) meningkatnya impor sementara ekspor turun, sehingga memperlebar external imbalance, dan (2) terjadinya excess demand akan menyebabkan inflasi meningkat. Hal ini dapat berpengaruh pada penurunan keunggulan

QE Journal | Vol.03 - No.01 - 15 
kompetitif negara tersebut yang akhirnya semakin memperburuk external imbalance. Tujuan semula untuk meningkatkan employment justru seringkali berdampak pada memburuknya current account pada balance of payment (Maipita et al, 2010).

Konflik antara external dan internal balance mengharuskan adanya instrumen kebijakan yang efektif dengan dampak negatif yang sekecil mungkin. Secara historis negara-negara berkembang sangat menggantungkan kebijakan ekspansi fiskal untuk mencapai pertumbuhan ekonomi. Model Mundell-Fleming dapat menjelaskan keadaan historis tersebut dengan aumsi yang telah memasukkan Balance of Payment (BOP), yaitu: (1) upah nominal dan harga fixed, (2) permintaan agregat berhubungan positif terhadap pengeluaran pemerintah $(G)$, output luar negeri $\left(\mathrm{Y}_{\mathrm{f}}\right)$, dan nilai tukar (e) berhubungan negatif dengan tingkat suku bunga domestik $\left(\mathrm{r}_{\mathrm{d}}\right)$, (3) permintaan uang merupakan fungsi negatif dari tingkat suku bunga dunia $\left(\mathrm{r}^{*}\right)$ dan fungsi positif terhadap tingkat pendapatan domestik, (4) supply uang secara negatif dipengaruhi oleh deviasi antara nilai tukar (e) dan target nilai tukar tertentu $\left(\mathrm{e}^{*}\right)$, (5) nilai perdagangan ditentukan oleh tingkat output domestik $\left(\mathrm{Y}_{\mathrm{d}}\right)$ dan tingkat output luar negeri ( $\mathrm{Y}_{\mathrm{f}}$ ), serta (6) capital account ditentukan oleh perbedaan tingkat suku bunga domestik dan luar negeri (Maipita et al, 2010; Husain and Chowdhury, 2001).

Derajad mobilitas kapital yang ditentukan melalui sensitivitas perbedaan suku bunga $\left(r\right.$ dan $r^{*}$ ) mempunyai peranan penting dalam model MF. Slope BOP menunjukkan derajad mobilitas kapital. Jika kurva BOP vertikal artinya tidak ada mobilitas kapital. Sebaliknya pada waktu mobilitas kapital sempurna, slope cenderung tak hingga (horisontal). Kurva BOP yang horizontal berimplikasi bahwa ada sedikit perbedaan antara tingkat suku bunga domestik dan asing yang akan mendorong adanya aliran kapital.

Gambar 1, menunjukkan kondisi dimana negara menganut sistem nilai tukar yang fleksibel (Romer, 2001; Sukirno, 2005). Pada kasus kurva BOP lebih curam dari kurva LM (Gambar 1a), kebijakan ekspansi fiskal akan menyebabkan BOP defisit dan nilai tukar riil terdepresiasi. Dampaknya, daya saing dan ekspor akan meningkat sehingga kurva IS maupun kurva BOP akan bergeser ke kanan. Titik keseimbangan yang baru menjadi E2 dimana efektifitas kebijakan fiskal menjadi sangat besar.

QE Journal | Vol.03 - No.01 - 16 
Kasus ketika kurva BOP lebih landai dari kurva LM (Gambar 1b), kebijakan fiskal yang ekspansif akan menyebabkan surplus BOP. Surplus ini akan mengakibatkan nilai tukar riil terapresiasi, daya saing menurun dan mengurangi ekspor. Keseimbangan akhir, baik kurva IS maupun BOP bergeser ke kiri sehingga keseimbangan eksternal dan internal yang baru berada di E2. Untuk nilai tukar yang fleksibel, semakin tinggi sensitivitas mobilitas kapital terhadap perubahan tingkat suku bunga, maka efektifitas kebijakan fiskal akan semakin berkurang.
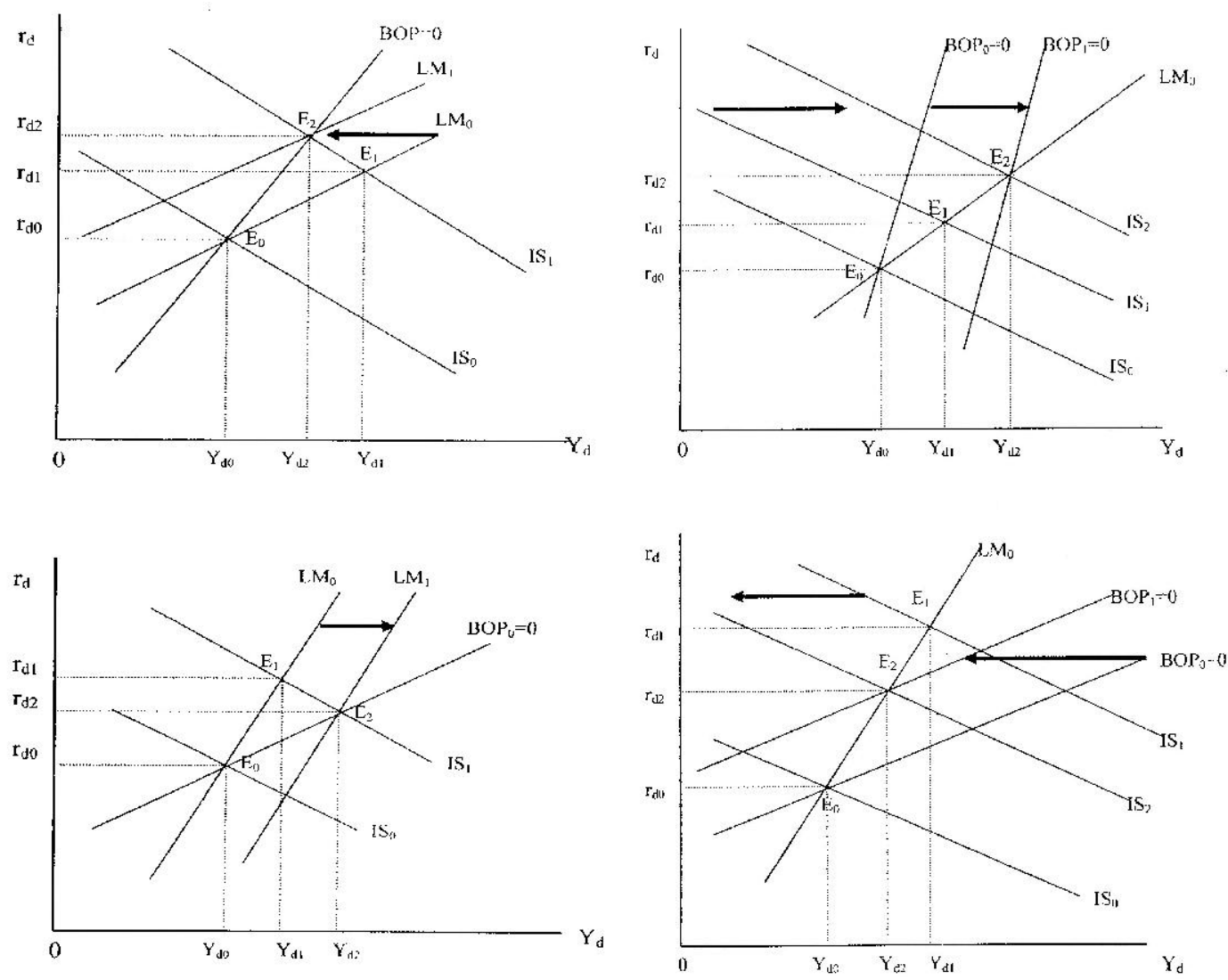

Sumber: Romer (2001), Sukirno (2005)

Gambar 1a. Efektifitas Kebijakan Fiskal pada Gambar 1b. Efektifitas Kebijakan Fiskal pada Kurs Tetap dan Modal Terbatas Kurs Fleksibel dan Modal Terbatas

Uraian di atas serta krisis moneter tahun 1997 merupakan bukti yang menjelaskan bahwa terdapat hubungan keterkaitan dan ketergantungan 
antara instrumen kebijakan moneter dengan indikator ekonomi makro dalam suatu sistem perekonomian. Perubahan pada suatu instrumen moneter dapat berakibat pada perubahan seluruh instrumen moneter lain dan indikator ekonomi makro (Fitrawaty, 2014).

Kajian ini bertujuan untuk menganalisis hubungan antara instrumen kebijakan moneter yang terdiri dari Operasi Pasar Terbuka (OPT), Giro Wajib Minimum (GWM ) dan Tingkat Bunga Fasilitas Diskonto (rDisk) melalui variabel antara berupa: Jumlah Uang Beredar (JUB), Tingkat Bunga Domestik (rDOM), Nilai Tukar Rupiah Terhadap Dolar US (EXC), Jumlah Ekspor (EKSPOR), Jumlah Impor (IMPOR), Jumlah Investasi (INV), inflasi (INF), dan tingkat pengangguran (UUNEM) terhadap Keseimbangan Neraca Pembayaran (BOP) di Indonesia.

\section{METODE PENELITIAN}

Uji stasioneritas dilakukan dengan uji unit root test disebut juga dengan stationary stochastic process (Bapepam \& LK, 2008), menggunakan Agumented Dickey Fuller (ADF). Berikutnya adalah menetapkan panjang lag menggunakan Akaike Information Criterion (AIC), Schwarz Information Criterion (SIC), dan Likelihood Ratio (LR) (Thomas, 1997; Greene, 2000; Alfirman dan Sutriono, 2006). Uji kointegrasi dilakukan menggunkan Johansen Criterion. Uji ini bertujuan untuk menentukan apakah variabel-variabel yang digunakan dalam penelitian berkointegrasi atau tidak (Bafadal, 2005; Ward, 2000). Estimasi model menggunakan Vector Autoregression (VAR), Structural Vector Autoregression (SVAR), uji Impulse Response Function (IRF) dan Variance Decomposition.

Model VAR banyak digunakan untuk melihat pengaruh kebijakan moneter, seperti dampak dinamis dari kebijakan moneter dan efektivitas kebijakan moneter (Gordon and Leeper, 1994; Rudebusch, 1998). Satu dari berbagai alasan mengapa model VAR cocok untuk melihat pengaruh suatu kebijakan adalah karena VAR menganggap semua variabel bersifat endogen. Selain itu VAR juga dapat mengestimasi persamaan identitas seperti halnya kausalitas Engel-Granger (Thomas, 1997; Gujarati, 1995). Spesifikasi model VAR yang digunakan diperlihatkan pada persamaan berikut: 


$$
\mathrm{V} A R(k), Z_{t}=A_{1} Z_{t-1}+A_{2} Z_{t-2}+\ldots .+A_{k} Z_{t-k}+\varepsilon_{t}
$$

dengan, $Z_{\mathrm{t}}$ adalah variabel time series yang dispesifikasi, $A_{\mathrm{k}}$ adalah matrik parameter berukuran $\mathrm{nx}$, dan $K$ adalah ordo atau lag. Ordo VAR (k) yang optimal ditentukan berdasarkan uji Akaike Information Criterion (AIC), Likelihood-Ratio (LR test), dan Scwarz Information Criterion (SIC). Apabila k=2 maka spesifikasi model VAR dalam penelitian ini adalah sebagai berikut:

$$
\begin{aligned}
& \mathrm{rBOP}_{\mathrm{t}}=a_{11} O P T_{t-1}+a_{12} G W M_{t-1}+a_{13} r D_{i s k_{t-1}}+a_{14} r J U B_{t-1}+a_{15} r D O M_{t-1} \\
& +a_{16} E X C_{t-1}+a_{17} E K S P O R_{t-1}+a_{18} I_{M P O R}+a_{19} I N V_{t-1}+a_{1.10} U N E M_{t-1} \\
& +a_{1.11} B O P_{t-1}+a_{1.12} I N F_{t-1}+a_{1.13} G R O W \\
& +a_{11} O P T_{t-2}+a_{12} G W M_{t-2}+a_{13} r D_{i s k_{t-2}}+a_{14} r J U B_{t-2}+a_{15} r D O M_{t-2} \\
& +a_{16} E X C_{t-2}+a_{17} E K S P O R_{t-2}+a_{18} I_{M P O R}+a_{19} I N V_{t-2}+a_{1.10} U_{N E M_{-2}} \\
& +a_{1.11} B O P_{t-2}+a_{1.12} I N F_{t-2}+a_{1.13} G R O W_{t-2}
\end{aligned}
$$

dengan OPT: operasi pasar terbuka, GWM : giro wajib minimum, rDiskonto: tingkat suku bunga sertifikat Bank Indonesia, JUB: jumlah uang beredar, rDOM: tingkat suku bunga domestik, EXC: nilai tukar, EKSPOR: ekspor, IMPOR: impor, INV: Investasi, INF: tingkat inflasi, GROW : pertumbuhan ekonomi, UNEM: tingkat pengangguran, BOP: Balance of Payment, dan Et: random disturbance.

Asumsi yang harus dipenuhi dalam alaisis VAR adalah: (1) semua variabel tak bebasnya harus bersifat stasioner, (2) semua sisaan bersifat white noise (memiliki rataan sama dengan nol dan varian yang konstan), (3) tidak terdapat korelasi diantara variabel bebasnya. Sebelum melakukan analisis menggunakan VAR atau VECM, terlebih dahulu dilakukan pengujian terhadap data, yaitu: (1) uji akar-akar unit (unit root test), (2) penetuan panjang lag, dan (3) uji kointegrasi (Johansen cointegration test) (Bapepam dan LK, 2008).

Varians struktural dari matrik kovarians diasumsikan menjadi diagonal, sehingga model dapat ditulis sebagai berikut.

$$
\begin{array}{r}
L O G[O P T]=u_{1} ; L O G[G W M]=u_{2} ; L O G[\text { rDiskonto }]=u_{3} ; L O G[J U B]=u_{4} \\
L O G[E X C]=u_{5} ; L O G[E X P O R]=u_{6} ; L O G[I M P]=u_{7} ; L O G[I N V]=u_{8} \\
\text { QE Journal | Vol.03 - No.01 - } 19
\end{array}
$$




$$
\begin{aligned}
& L O G[B O P]-C_{1} L O G[O P T]-C_{2} L O G[G W M]-C_{3} L O G\left([\text { Rdiskonto }]-C_{4} L O G[J U B]\right. \\
& -C_{5} L O G[R D O M]-C_{6} L O G[E X C]-C_{7} L O G[E X P O R]-C_{8} L O G[I M P]-C_{9} L O G[I N V] \\
& -C_{10} L O G[U N E M P]=u_{10} \\
& L O G[B O P]-C_{1} L O G[O P T]-C_{2} L O G[G W M]-C_{3} L O G\left([\text { Rdiskonto }]-C_{4} L O G[J U B]\right. \\
& -C_{5} L O G[R D O M]-C_{6} L O G[E X C]-C_{7} L O G[E X P O R]-C_{8} L O G[I M P]-C_{9} L O G[I N V] \\
& -C_{10} L O G[U N E M P]=u_{10} \\
& L O G[I N F]-C_{1} L O G[O P T]-C_{2} L O G[G W M]-C_{3} L O G\left([\text { Rdiskonto }]-C_{4} L O G[J U B]-C_{5} L O G[R D O M]\right. \\
& -C_{6} L O G[E X C]-C_{7} L O G[E X P O R]-C_{8} L O G[I M P]-C_{9} L O G[I N V]-C_{10} L O G[U N E M P] \\
& -C_{11} L O G[B O P]=u_{11} \\
& L O G[G R O W]-C_{1} L O G[O P T]-C_{2} L O G[G W M]-C_{3} L O G\left([\text { Rdiskonto }]-C_{4} L O G[J U B]-C_{5} L O G[R D O M]\right. \\
& -C_{6} L O G[E X C]-C_{7} L O G[E X P O R]-C_{8} L O G[I M P]-C_{9} L O G[I N V]-C_{10} L O G[U N E M P] \\
& -C_{11} L O G[B O P]-C_{12} L O G[I N F]=u_{12}
\end{aligned}
$$

Data yang digunakan dalam penelitian ini adalah data sekunder dalam bentuk kuartal dari tahun 2000-2011, berasal dari Bank Indonesia, Badan Pusat Statistik dan sumber lain yang relevan.

\section{HASIL DAN PEMBAHASAN}

Hasil estimasi pengaruh variabel kebijakan moneter terhadap Balance of Payment secara lengkap diperlihatkan pada Tabel 1.

Tabel 1. Hasil Estimasi SVAR Terhadap Neraca Pembayaran (BOP)

\begin{tabular}{lcclcc}
\hline \multicolumn{1}{c}{ Variable } & Coeficient & Probability & \multicolumn{1}{c}{ Variable } & Coeficient & Probability \\
\hline C9 (OPT) & 2.045633 & 0.0000 & C14 (EXPOR) & 0.641494 & 0.0000 \\
C10 (GWM) & -0.454719 & 0.0020 & C15 (IMP) & -4.849115 & 0.0000 \\
C11 (rDisk) & -1.102335 & 0.0000 & C16 (INV) & 2.329909 & 0.0000 \\
C12(rDOM) & 0.078387 & 0.5950 & C17 (UNEMP) & -3.304541 & 0.0000 \\
C13 (EXC) & -1.444291 & 0.0000 & & & \\
\hline
\end{tabular}

Sumber: Hasil Penelitian

Dari Tabel 1, terlihat bahwa pada tingkat $\alpha=0.005$, semua variabel signifikan mempengaruhi BOP, kecuali variabel tingkat suku bunga domestik (rDOM). Artinya, guncangan (shock) setiap variabel tersebut (kecuali variabelr DOM) akan signifikan mempengaruhi neraca pembayaran (BOP). 
Variabel kebijakan moneter memiliki pengaruh terhadap neraca pembayaran dengan arah yang berbeda. Peningkatan variabel OPT berdampak positif terhadap neraca pembayaran dengan koefisien sebesar 2,0456. Ini berarti bahwa bila variabel OPT mengalami peningkatan sebesar 1 milyar, maka BOP juga akan meningkat sebesar 2,0456 milyar. Kondisi ini sesuai dengan teori, di mana bila bank sentral menaikkan penjualan surat berharga sebagai instrumen OPT, menyebabkan neraca perdagangan menjadi surplus.

Operasi pasar terbuka merupakan salah satu instrumen kebijakan moneter dengan sasaran antaranya adalah jumlah uang beredar. Bentuk kegiatan ini seperti jual beli surat-surat berharga jangka pendek dan jangka panjang dalam rangka mengatur jumlah uang beredar atau suku bunga jangka pendek dan jangka panjang.

Salah satu sekuritas yang sering digunakan Bank Indonesia untuk mengendalikan jumlah uang beredar adalah Sertifikat Bank Indonesia (SBI). Jika bank sentral bermaksud menambah jumlah uang beredar maka bank sentral akan membeli surat-surat berharga untuk meningkatkan kemampuan bank-bank memberikan pinjaman sehingga jumlah uang beredar meningkat (Pohan, 2008).

Berbeda dengan variabel OPT, variabel GWM dan rDisk justru berpengaruh secara negatif terhadap BOP. Dengan kata lain, bila giro wajib minimum (GWM) atau tingkat suku bunga diskonto (rDisk) menaik, maka neraca pembayaran akan menurun. Koefisien GWM dan rDisk masingmasing sebesar -0,4547 dan -1,1023 menandakan bahwa bila giro wajib minimum naik sebesar 1 milyar, dapat menyebabkan turunnya neraca pembayaran sebesar 0,4547 mlyar. Dan bila tingkat suku bunga diskonto naik sebesar 1 persen, maka neraca pembayaran dapat menurun sebesar 1,1023 milyar.

Secara teori, kenaikan GWM akan meningkatkan jumlah aktiva luar negeri, selanjutnya meningkatkan cadangan devisa dan akhirnya neraca pembayaran menjadi surplus. Namun sperti dijelaskan sebelumnya (Tabel 1) bahwa GWM justru berpengaruh negatif dengan BOP. Kondisi ini tentu tidak sesuai dengan teori, dimana kebijakan moneter kontraktif dengan manikkan GWM seharusnya berpengaruh positif terhadap BOP. Meningkatnya GWM mestinya akan membuat jumlah aktiva luar negeri

QE Journal | Vol.03 - No.01 - 21 
meningkat dan selanjutnya akan menambah cadangan devisa sehingga neraca pembayaran semakin membaik. Ketidak sesuaian dengan teori ini dapat disebabkan karena kenaikan GWM lebih kecil dibanding dengan kenaikan impor yang terjadi sehingga menyebabkan neraca pembayaran menurun.

Kembali pada Tabel 1, bahwa hasil kajian ini menunjukkan hubungan yang negatif antara variabel rDisk dengan BOP. Kondisi ini juga tidak sesuai dengan teori, misalnya ketika Bank sentral menaikan BI rate, maka selisih tingkat suku bunga domestik dengan suku bunga luar negeri akan semakin melebar. Kondisi ini tentu akan memicu investor asing untuk menanamkan modalnya atau menyimpan uangnya atau membeli berbagai instrumen keuangan di dalam negeri. Di satu sisi situasi ini memberikan keuantungan yang lebih besar pagi para investor, sementara di sisi lain dengan adanya aliran masuk modal (capital in flow), akan berdampak terhadap peningkatan atau perbaikan neraca pembayaran.

Variabel makro yang berpengaruh positif dan signifikan terhadap neraca pembayaran adalah ekspor dan investasi. Sedangkan nilai tukar, impor dan tingkat pengangguran memiliki pengaruh yang negatif dan signifikan. Ini berarti bahwa bila ekspor dan investasi meningkat maka neraca perdagangan juga akan meningkat dan sebaliknya. Sedangkan bila nilai tukar, impor dan tingkat pengangguran naik, akan menurunkan neraca pembayaran. Besarnya pengaruh masing-masing terhadap neraca pembayaran diperlihatkan oleh nilai koefisien masing-masing variabel pada Tabel 1.

Keadaan ini sesuai dengan teori, di mana bila ekspor meningkat maka devisa akan bertambah dan neraca pembayaran akan membaik. Demikian juga dengan investasi. Kemudian bila nilai tukar meningkat, maka rupiah akan terdepresiasi. Bila impor meningkat, maka devisa akan berkurang dan ini akan memperburuk neraca pembayaran yang ada.

Hasil penaksiran SVAR dapat digunakan untuk menganalisis fungsi respon menuju jalur keseimbangan. Analisis ini dikenal dengan Impulse response function (IRF), digunakan untuk melihat pengaruh perubahan satu standar deviasi suatu variabel terhadap variabel itu sendiri atau variebel lainnya. Visualisasi fungsi respon menuju jalur keseimbangan ditunjukkan pada lampiran.

QE Journal | Vol.03 - No.01 - 22 
Pengaruh shock variabel kebijakan moneter sebesar satu standar deviasi terhadap variabel neraca pembayaran diperlihatkan pada Tabel 2, sedangkan pengaruh shock variabel makro atau variabel antara diperlihatkan pada Tabel 3.

Tabel 2 dan Tabel 3 terdiri dari 20 periode. Karena data penelitian ini merupakan data kuartalan selama 12 tahun, maka satu periode setara dengan waktu 2,5 bulan. Untuk memudakan analisis, periode tersebut dibagi ke dalam 3 jangka waktu yaitu jangka pendek, menengah dan panjang. Jangka pendek yang dimaksud adalah selang seperempat pertama dari total waktu penelitian (periode 1-5). Jangka menengah adalah selang waktu seperempat kedua dari total waktu penelitian (periode 6-10), sedangkan jangka panjang adalah jangka lebih setengah dari total waktu penelitian (periode 11-20).

Tabel 2. Respon Variabel Neraca Pembayaran (BOP) terhadap Variabel Kebijakan Moneter (OPT, GWM, dan rDisk)

\begin{tabular}{cccccccc}
\hline Periode & OPT & GWM & \multicolumn{1}{c}{ rDisk } & Periode & \multicolumn{1}{c}{ OPT } & \multicolumn{1}{c}{ GWM } & \multicolumn{1}{c}{ rDisk } \\
\hline 1 & 0.155789 & -0.065472 & -0.412753 & 11 & 0.135005 & -0.068131 & -0.282899 \\
2 & 0.048704 & -0.516542 & -0.328944 & 12 & -0.204336 & -0.005543 & -0.020378 \\
3 & -0.320101 & 0.075882 & 0.494278 & 13 & -0.210789 & 0.206245 & 0.143088 \\
4 & -0.302758 & 0.120805 & 0.295121 & 14 & 0.033302 & 0.236731 & -0.001099 \\
5 & 0.081130 & 0.044618 & -0.152420 & 15 & 0.096979 & 0.023472 & -0.137833 \\
6 & 0.188689 & -0.105742 & -0.123646 & 16 & -0.113875 & -0.168330 & -0.029573 \\
7 & -0.189350 & -0.253008 & 0.048386 & 17 & -0.241114 & -0.109687 & 0.160201 \\
8 & -0.245655 & -0.030295 & 0.144658 & 18 & -0.069238 & 0.032738 & 0.143045 \\
9 & 0.095733 & 0.208851 & 0.023067 & 19 & 0.163781 & 0.003278 & -0.050292 \\
10 & 0.339239 & 0.129189 & -0.235581 & 20 & 0.142660 & -0.140696 & -0.132243 \\
\hline
\end{tabular}

Sumber: Hasil Penelitian

Shock variabel OPT sebesar satu standar deviasi berpengaruh terhadap neraca pembayaran. Secara periodek, pengaruh tersebut berganti antara positif dengan negatif (lihat Tabel 2). Shock variabel OPT pada dua periode pertama berdampak positif terhadap BOP, artinya shock tersebut akan menaikkan BOP. Namun untuk dua periode berikutnya justru berdampak negatif, dan seterusnya. Pengaruh shock satu standar deviasi GWM dan rDisk terhadap nilai BOP juga relatif berfluktuasi seperti pengaruh variabel OPT. 
Tabel 3 memperlihatkan bagaimana pengaruh shock variabel makro lainnya sebesar satu standar deviasi tehadap neraca pembayaran.

Tabel 3. Respon Variabel Neraca Pembayaran terhadap Variabel Antara

\begin{tabular}{rrrrrrrr}
\hline Period & \multicolumn{1}{c}{ EXC } & EXPORT & IMPORT & INVEST & \multicolumn{1}{c}{ UNEMP } & \multicolumn{1}{l}{ GROW } & \multicolumn{1}{c}{ INF } \\
\hline & & & & & & & \\
1 & -0.128079 & 0.068337 & 0.203812 & 0.145565 & -0.189196 & 0.000000 & 0.000000 \\
2 & -0.308804 & 0.311405 & -0.179822 & 0.316041 & 0.084884 & -0.014554 & 0.093754 \\
3 & -0.055510 & 0.020619 & -0.102904 & -0.204572 & 0.005764 & -0.129174 & -0.096013 \\
4 & 0.255855 & 0.178783 & 0.654960 & -0.284982 & 0.025194 & -0.192589 & -0.143065 \\
5 & 0.278600 & -0.061978 & 0.586677 & -0.086022 & -0.199646 & -0.067603 & 0.065759 \\
6 & -0.107393 & 0.040910 & -0.145882 & 0.006926 & -0.057503 & 0.067992 & 0.231922 \\
7 & -0.245166 & 0.058311 & -0.371611 & -0.029857 & 0.126447 & 0.021383 & 0.182507 \\
8 & 0.050353 & 0.014703 & 0.057019 & -0.093386 & 0.049544 & 0.002468 & -0.070897 \\
9 & 0.228118 & -0.123680 & 0.264838 & -0.119036 & -0.084482 & 0.032280 & -0.159461 \\
10 & 0.063735 & -0.084894 & -0.033256 & 0.012417 & -0.074935 & 0.113859 & -0.028772 \\
11 & -0.183377 & 0.048394 & -0.395179 & 0.179126 & 0.061807 & 0.096043 & 0.054738 \\
12 & -0.136502 & 0.066069 & -0.320989 & 0.124508 & 0.127897 & 0.020484 & -0.082931 \\
13 & 0.094878 & 0.013666 & 0.112340 & -0.000804 & 0.046820 & -0.044068 & -0.193516 \\
14 & 0.133311 & -0.022747 & 0.267191 & 0.015999 & -0.053908 & -0.037310 & -0.068623 \\
15 & -0.088985 & 0.044898 & -0.005485 & 0.108523 & -0.019635 & -0.002126 & 0.135235 \\
16 & -0.232629 & 0.115800 & -0.194678 & 0.099204 & 0.078902 & -0.026340 & 0.179204 \\
17 & -0.095670 & 0.088881 & 0.021727 & -0.029619 & 0.072357 & -0.080866 & 0.063168 \\
18 & 0.092773 & 0.010559 & 0.306943 & -0.118818 & -0.025652 & -0.084561 & -0.000194 \\
19 & 0.063834 & -0.007012 & 0.231222 & -0.067682 & -0.069484 & -0.028795 & 0.081767 \\
20 & -0.099444 & 0.043881 & -0.079839 & 0.022761 & -0.001773 & 0.007706 & 0.155995 \\
\hline
\end{tabular}

Sumber: Hasil Penelitian

Untuk jangka pendek akumulasi respon kejutan acak atau dampak pengganda dari variabel OPT, EKSPOR, IMPOR, dan INV akan meningkatkan BOP, dari hasil ini hanya kenaikan impor akan menyebabkan kenaikan BOP. Sedangkan peningkatan dari variabel seperti GWM, rDiskonto, EXC, dan UNEMP, pada periode jangka pendek akan menurunkan variabel BOP, kondisi ini sesuai dengan ekspektasi teori.

Selanjutnya pada jangka menengah, akumulasi respon kejutan acak atau dampak pengganda sesuai dengan ekpektasi teori dimana peningkatan dari variabel OPT, rDom, EXPOR, INV, BOP akan meningkatkan BOP. Sementara untuk kejutan acak peningkatan variabel GWM, rDiskonto, EXC, IMPOR, UNEMP akan menurunkan penerimaan BOP. Kondisi ini juga sesuai dengan teori. 
Dalam jangka panjang, akumulasi respon kejutan acak juga sesuai dengan teori, dimana peningkatan variabel OPT, EKSPOR, dan INV akan meningkatkan penerimaan BOP.

\section{SIMPULAN DAN SARAN}

\section{Simpulan}

Pada tingkat $\alpha=0,05$, variabel instrumen kebijakan moneter berupa operasi pasar terbuka, giro wajib minimum, dan tingkat suku bunga diskonto secara signifikan mempengaruhi neraca pembayaran. Bahkan semua variabel makro ekonomi sebagai antara juga signifikan mempengaruhi variabel neraca pembayaran, kecuali variabel tingkat suku bunga domestik. Ini berarti bahwa terdapat keterkaitan yang erat antara instrumen kebijakan moneter dengan neraca pembayaran di Indonesia pada periode waktu penelitian.

Hubungan atau keterkaitan antara variabel kebijakan moneter dengan variabel neraca pembayaran memiliki arah yang berbeda. Variabel operasi pasar terbuka mempengaruhi neraca pembayaran dengan arah positif, sedangkan giro wajib minimum dan tingkat suku bunga diskonto berpengaruh secara negatif.

Respon neraca pembayaran terhadap shock variabel makro (variabel antara) sebesar satu standar deviasi memiliki arah dan besaran yang berbeda di atara variabel baik dalam jangka pendek, menengah, dan panjang.

\section{Saran}

Untuk menjaga keseimbangan neraca pembayaran, perlu sinkronisasi yang baik antara kebijakan moneter dan fiskal. Selain itu, perlu kehati-hatian dalam mengambil kebijakan berkenaan dengan beberapa variabel makro (antara) yang memili hubungan negatif dengan neraca pembayaran.

\section{DAFTAR PUSTAKA}

Alfirman, Luki., dan Edy Sutriono. 2006. Analisis Hubungan Pengeluaran Pemerintah dan Produk Domestik Bruto dengan Menggunakan Pendekatan Granger Causality dan Vector Autoregression. Jurnal Keuangan Publik. 4(1):25-66. 
Bafadal, Azhar. 2005. Dampak Defisit dan Utang Pemerintah Terhadap Stabilitas Makroekonomi. Disertasi. Sekolah Pascasarjana Institut Pertanian Bogor.

Bapepam \& L.K. (Badan Pengawas Pasar Modal dan Lembaga Keuangan. 2008. Analisis Hubungan Kointegrasi dan Kausalitas serta Hubungan Dinamis Antara Aliran Modal Asing, Perubahan Nilai Tukar dan Pergerakan IHSG di Pasar Modal Indonesia. Departemen Keuangan Republik Indonesia.

Engle, R.F., and Granger, C.W.J. 1987. Co-Integration and Error Corection: Representation, Estimation, and Testing. Econometrica 55. 251-76.

Fitrawaty. 2014. Analisis Interdependensi Kebijakan Moneter dan Pengaruhnya terhadap Indikator Ekonomi Makro Indonesia. Diseratasi. Fakultas Ekonomi Universitas Sumatera Utara.

Gordon, David. B., \& Eric M. Leeper. 1994. The Dynamic Impact of Monetary Poicy: An Excercises in Tentative Identification. Journal of Political Economy. 102(6):1228-1247.

Greene,William, H. 2000. Econometric Analysis. 4th. New Jersey: Prentice Hall.

Gujarati, Damodar. 1995. Basic Econometrics. McGraw-Hill: Singapore.

Husain, A., \& Chowdhry, A. 2001. Open-Economy Macroeconomics for Developing Countries. Northampton: Edwar Elger, Cheltenham.

Maipita, Indra., Jantan, M.D., Razak, Noor Azam Abd. 2010. Dampak Kebijakan Fiskal Terhadap Kinerja Ekonomi dan Angka Ke miskinan di Indonesia. Buletin Ekonomi Moneter dan Perbankan Bank Idonesia 12(4):421-456.

Pohan, Aulia. 2008. Potret Kebijakan Moneter Indonesia. PT. Raja Grafindo Persada. Jakarta.

Romer, D. 2001. Advanced Macroeconomics. Second Edition. New York: McGraw-Hill Book Co.

Rudebusch, G. 1998. Do Measures of Monetary Policy in a VAR Make Sense? International Economic Review 39: 907 - 931.

Sukirno, S. 2005. Makroekonomi Modern: Perkembangan Pemikiran Dari Klasik Hingga Keynesian Baru. Jakarta: Rajawali Press.

QE Journal | Vol.03 - No.01 - 26 
Thomas, Loyd. B. 1997. Money, Banking and Financial Market. International Edition. Mc Graw-Hill. New-York. USA.

Ward, B. D., and H. Siregar. 2000. The Role of Aggregate Demand Shocks in Explaining Indonesian Macro-Economic Fluctuations. Commerce Division Discussion Paper No. 86. Lincoln University. Canterbury. 